\title{
ON THE ORIGIN OF ABLATION HOLLOWS (POLYGONS) ON SNOW
}

\author{
By Alfred Jahn \\ (Geographical Institute, University of Wrocław, Wrocław, Poland) \\ and MieczysŁaw KŁapA
}

(Research Station of the Institute of Geography, Polish Academy of Sciences, Tatra Mountains, Hala Gąsienicowa, Poland)

\begin{abstract}
Ablation polygons on snow have been examined, mainly in the Tatra Mountains, both by field observation and by experiment. The polygons are initiated under peculiar climatic conditions-mostly when the melting of snow is somewhat slow and is accompanied simultaneously by the metamorphism of snow. A thick snow cover appears to be a prerequisite of this process. A detailed analysis of the problem of dirt concentration in snow, due to ablation, reveals the major role played by adhesion in this process. The concentration of dirt is due to lateral movement of the material and this is intrinsically related to the microelements of the snow surface.

The origin and development of ablation polygons do not depend on the presence of dirt in the snow; on the contrary, the process of dirt concentration and its effects are dependent on the evolution of polygonal forms.
\end{abstract}

RÉsumé. Sur l'origine des nids d'abeille (polygones) d'ablation sur la neige. Polygones d'ablation sur la neige ont été examinés, surtout dans les montagnes du Tatra, par observations sur le terrain et par expérimentation. Les polygones prennent naissance dans des conditions climatiques singulières - surtour quand la fonte des neiges est assez lente et accompagnée par la métamorphose de la neige. Un manteau de neige assez épais semble etre necessaire pour ce processus. Une analyse détaillée du problème de la concentration des impuretés par ablation, révéle le rôle important de l'adhesion. La concentration des impuretés est le resultat du mouvement latéral de la matière, et celui-ci est fondamentalement lié aux micro-éléments sur la surface de la neige.

L'origine et l'évolution des polygones d'ablation ne dépend pas de la présence des impuretés dans la neige; au contraire, le processus de concentration des impuretés et ces effets dépendent de l'évolution des formes polygonales.

Zusammenfassung. Über die Entstehung von Ablationslöchern (Polygonen) im Schnee. Ablationspolygone im Schnee - vor allem in der Tatra - wurden sowohl durch Feldbeobachtungen als auch durch Experimente untersucht. Die Polygone entstehen unter besonderen klimatischen Bedingungen, vornehmlich dann, wenn der Schnee relativ langsam schmilzt und gleichzeitig eine Metamorphose des Schnees stattfindet. Eine dicke Schneedecke scheint eine Voraussetzung für diesen Prozees zu sein. Eine detailierte Analyse des Problems der von der Ablation abhängigen Schmutzkonzentration im Schnee zeigt, dass die Adhäsion eine wesentliche Rolle bei diesem Vorgang spielt. Die Schmutzkonzentration wird durch seitliche Bewegung des Materials verursacht, die wiederum in engstem Zusammenhang mit den Mikroelementen der Schneeoberfläche steht.

Die Entstehung und Entwicklung von Ablationspolygonen setzt nicht das Vorhandensein von Schmutz im Schnee voraus; im Gegenteil, der Prozess der Schmutzkonzentration und seine Auswirkungen ist von der Bildung der Polygonformen abhängig.

\section{INTRODUGTION}

The surface of melting snow has certain specific forms whose origin has not been fully elucidated until now. Broadly speaking, these forms can be grouped as hollows and mounds, the first forming on clean dirt-free snow and the second owing their existence largely to the participation of some foreign material, both mineral (dust and sand) and organic (fir or pine needles, remnants of grass and algae). Particular interest is aroused by ablation forms of geometric appearance, such as polygonal ablation hollows and dirt cones. Their origin has been discussed in a number of papers, many of them published in this Journal.

Polygonal ablation hollows of this type were known to Heim (I885); and Hamberg (I 907), the author of a classical work on the properties of snow cover, suggested that undulating movement of warm air masses passing above the snow surface plays an important part in the initiation of regular ablation forms. Westman (1913), who illustrated his work with excellent photographs of polygonal hollows on snow, was inclined to consider the dust brought in by the wind as a factor contributing to the formation of the hollows, either causing melting inside the snow or providing protection. Dobrowolski (1923), in his study Historja naturalna lodu, 
gave a considerable amount of thought to polygonal ablation forms which he referred to as "waves of melting". He made it clear that the hollows are formed irrespective of the presence or absence of dirt deposited on the snow, and he attributed their formation not merely to the action of the sun but primarily to convection heat.

These references to earlier studies are worth quoting to show that the problem of ablation hollows was well known in the early twentieth century. However, there have been more recent attempts to resolve the question of the origin of these forms. Leighly's (1948) work described some hitherto unknown ablation forms on downward-facing surfaces of firn and ice ("overhanging surfaces"). He put forward the idea of "cellular convection" of the air in contact with the surface of the snow and explained thereby the process of the formation of polygonal hollows. This concept was supported by Richardson (1954). Further progress in solving the problem of polygonal patterns on snow was achieved by Ball (1954), whose theory of "normal trajectory" offered an adequate solution to the question of the concentration of dirt in melting snow. Sekyra (1964) ascribed the existence of ablation hollows to the process of sublimation of the snow in a dry mountainous environment. Two years later, Ashwell and Hannell (I966) attempted an experimental explanation of the origin of these forms.

It is to the problem of ablation hollows that we wish to relate our observations which have extended over many years. Our observations have been made mainly in the Polish mountains (the Tatra and Sudetic Mountains) and in Vestspitsbergen. In 1966 and 1967 we also did some experimental work at the Research Station of the Institute of Geography, Polish Academy of Sciences, in the Tatra Mountains (Hala Gąsienicowa, altitude I $520 \mathrm{~m}$ ) above the timber line.

\section{Conditions Governing the Ocgurrence of Ablation Hollows}

In the Tatra Mountains, at altitudes of about $\mathrm{I}$ ooo-2 $000 \mathrm{~m}$, the occurrence of ablation hollows on snow patches is a common phenomenon in the spring and summer months. In the Sudetic Mountains, especially in their highest part (the Karkonosze), ablation hollows have been noticed only at altitudes above $800 \mathrm{~m}$. These forms occur exclusively in the mountains and not in the low land, in spite of the fact that the snow cover in the latter region stays for some time in winter and is subject to ablation. It would follow, therefore, that necessary for the development of these characteristic ablation forms are a sufficient thickness of snow cover (which amounted to $\mathrm{I}-2 \mathrm{~m}$ in that part of the Tatra Mountains we have examined) and certain climatic characteristics such as low temperatures in spring, i.e. slow melting, considerable losses of snow due to evaporation, the melting action of winds, severe turbulence in air currents due to the relief of obstacles, natural conditions favouring the shading of snow patches and the warming-up influence of the rock surface exposed by the disappearance of snow. Clearly, it is not the absolute altitude by itself, but the conditions of climate, as related to altitude and latitude, that are of prime importance here. In this respect, the observations of Richardson and Harper ( 1957 ) appear to be correct. The problem of ablation forms on snow should be approached in much the same way as other morpho-climatic phenomena, e.g. periglacial forms. For instance, in Vestspitsbergen ablation hollows and cones occur at sealevel.

The most characteristic forms of ablation hollows were found on snow patches in the Tatra Mountains in deep shaded valleys and cirques, especially in the vicinity of rocky slopes (Kłapa, I963). Regular patterns of polygonal ablation hollows are seen every year on the snow patches at the bottom of a deep karst gorge in Kościeliska valley, at an altitude of I $200 \mathrm{~m}$ (Fig. I). Generally speaking, these forms are independent of the slope of the snow surface, i.e. in most cases they show no deformation related to slope (Fig. 2). Nevertheless, we have noticed some typical development of ablation forms, which were due to the exposure of the snow patch but not directly to its angle of slope. Thus, apart from regular polygonal hollows, there are step-like systems of forms related to exposure of the snow surface or insolation 


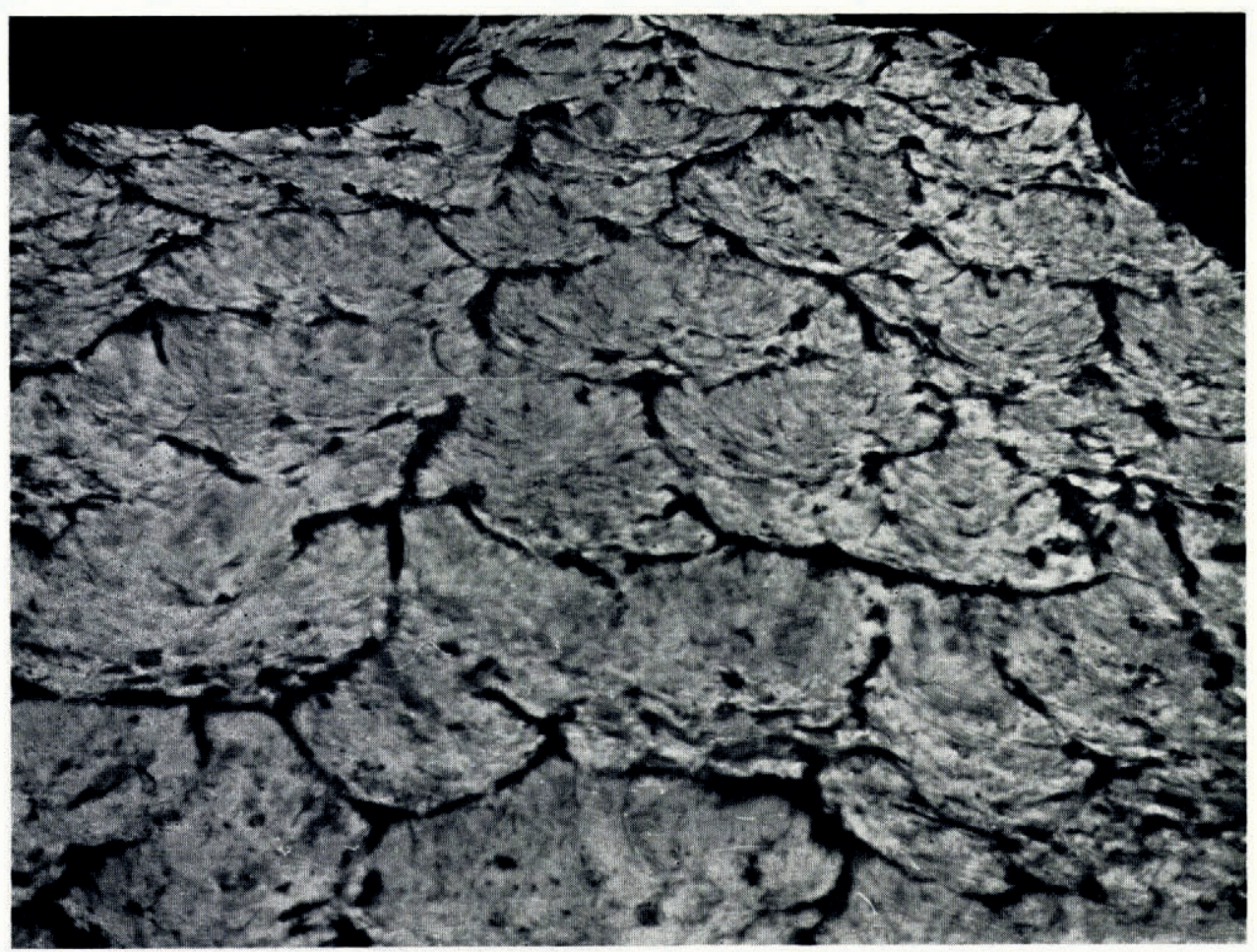

Fig. I. Regular pattern of ablation polygons in Kosicieliska valley (altitude I $200 \mathrm{~m}$ ), in the Tatra Mountains. The photograph was taken in June 1952

or to the action of the orientated winds, i.e. those blowing in one direction only, and the melting of snow (Fig. 3). In the Karkonosze Mountains, typical polygonal ablation hollows on snow were only found in fir woods at the beginning of May. The timber line was apparently the boundary for these ablation forms in clearings in the woods. In this case, too, shading and possibly also large quantities of fir needles must have been conducive to the formation of the hollows.

The occurrence of ablation polygons on overhanging snow surfaces presents a separate problem. In the area examined, the polygons are a common phenomenon on walls and inverted surfaces, such as on roofs of snow tunnels, under natural and artificial bridges, and on vertical and overhanging walls of snow drifts. This problem has been discussed by Leighly (I948), Richardson (I 954) and Lliboutry (I964-65). Lliboutry advanced an hypothesis that ablation by infra-red and dispersed rays, as well as turbulence in air masses contained in the glacier and snow tunnels, provide conditions for developing hollows similar to those on bare (uncovered) snow surfaces. This hypothesis appears to be correct. From our observations it follows that surface and under-surface polygons cannot be regarded separately, since there is no clear-cut dividing line between them. On the contrary, there are a number of intermediate forms, ranging from typical surface polygons on horizontal snow patches, through ablation hollows on the sides of vertical snow masses (snow drifts), to inverted under-surface polygons.

The question that now arises is to what extent the origin or development of ablation hollows on snow is dependent upon the admixture of mineral and organic material. On the basis of our observations from areas differing very considerably, it can be inferred that meltingout of foreign material from the snow and the formation of ablation hollows - as shown 


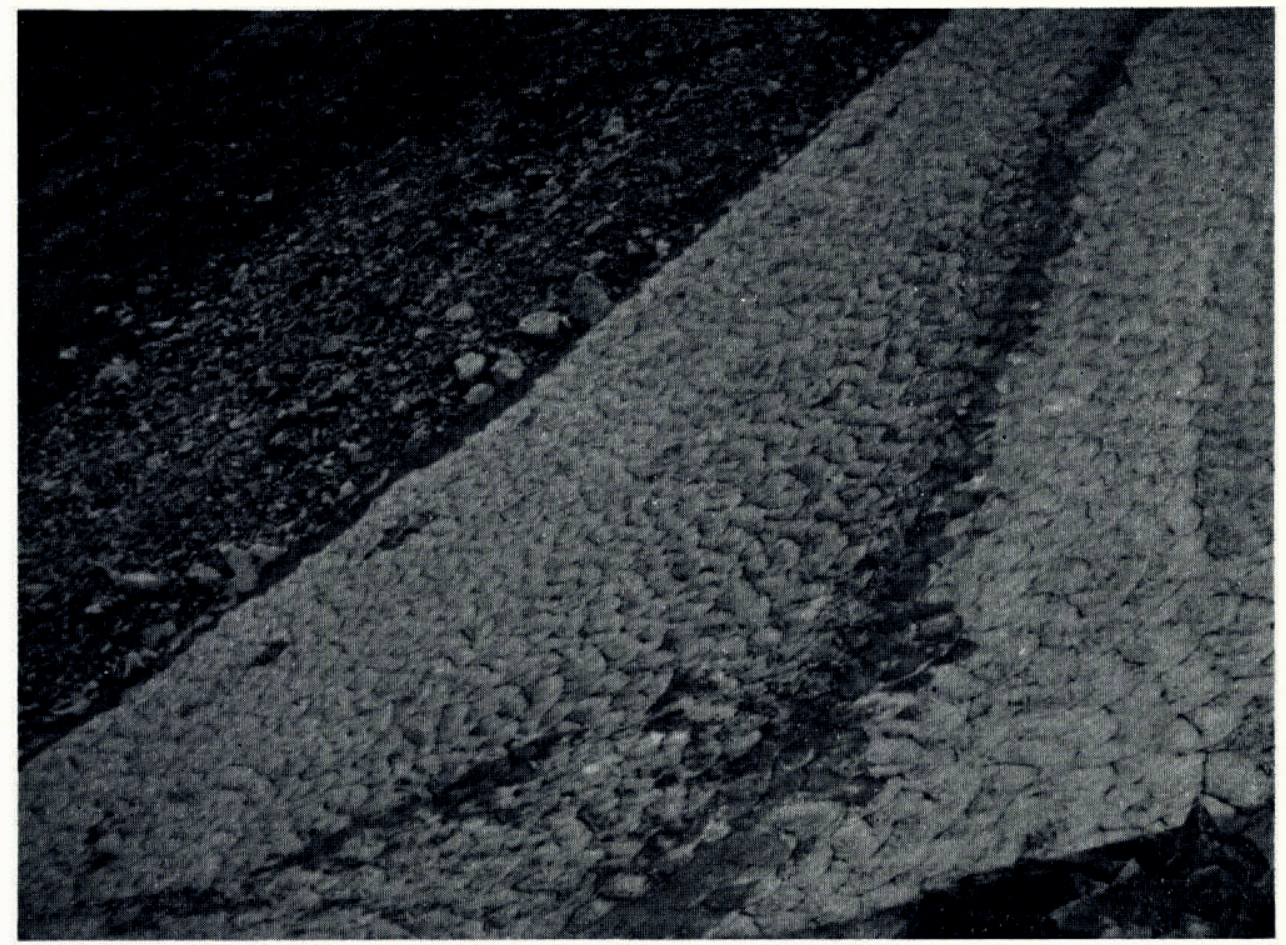

Fig. 2. Ablation polygons on a snow patch in the valley of the Paniszczyca river in the Tatra Mountains (altitude I $800 \mathrm{~m}$ ), in August 1966. The slope of the snow patch is $35^{\circ}$. Polygon forms are independent of the slope of the snow surface

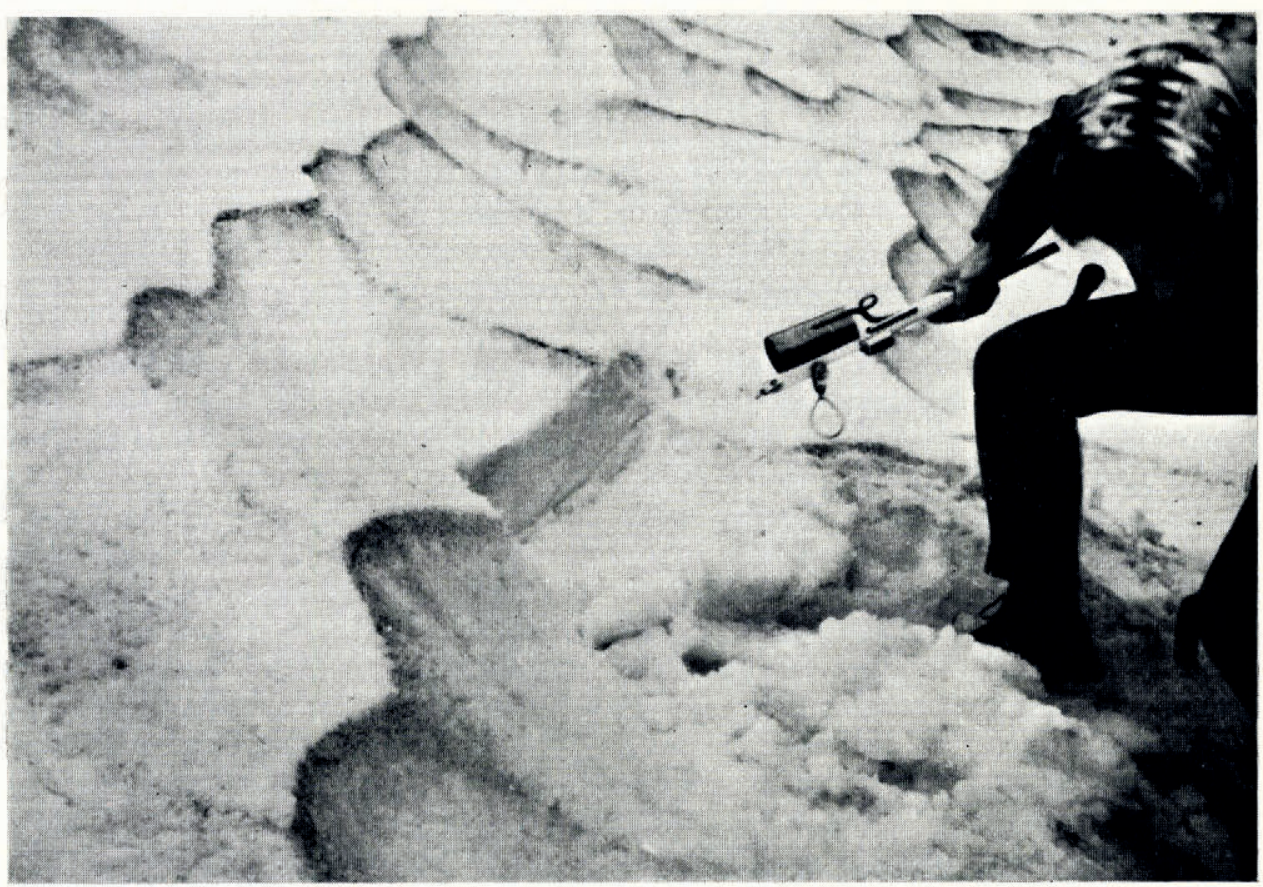

Fig. 3. A step-like arrangement of ablation forms. Melted-out material has collected on a vertical wall. (Czarny Staw Gaqsienicowy, Tatra Mountains, altitude I $640 \mathrm{~m}$ ) 


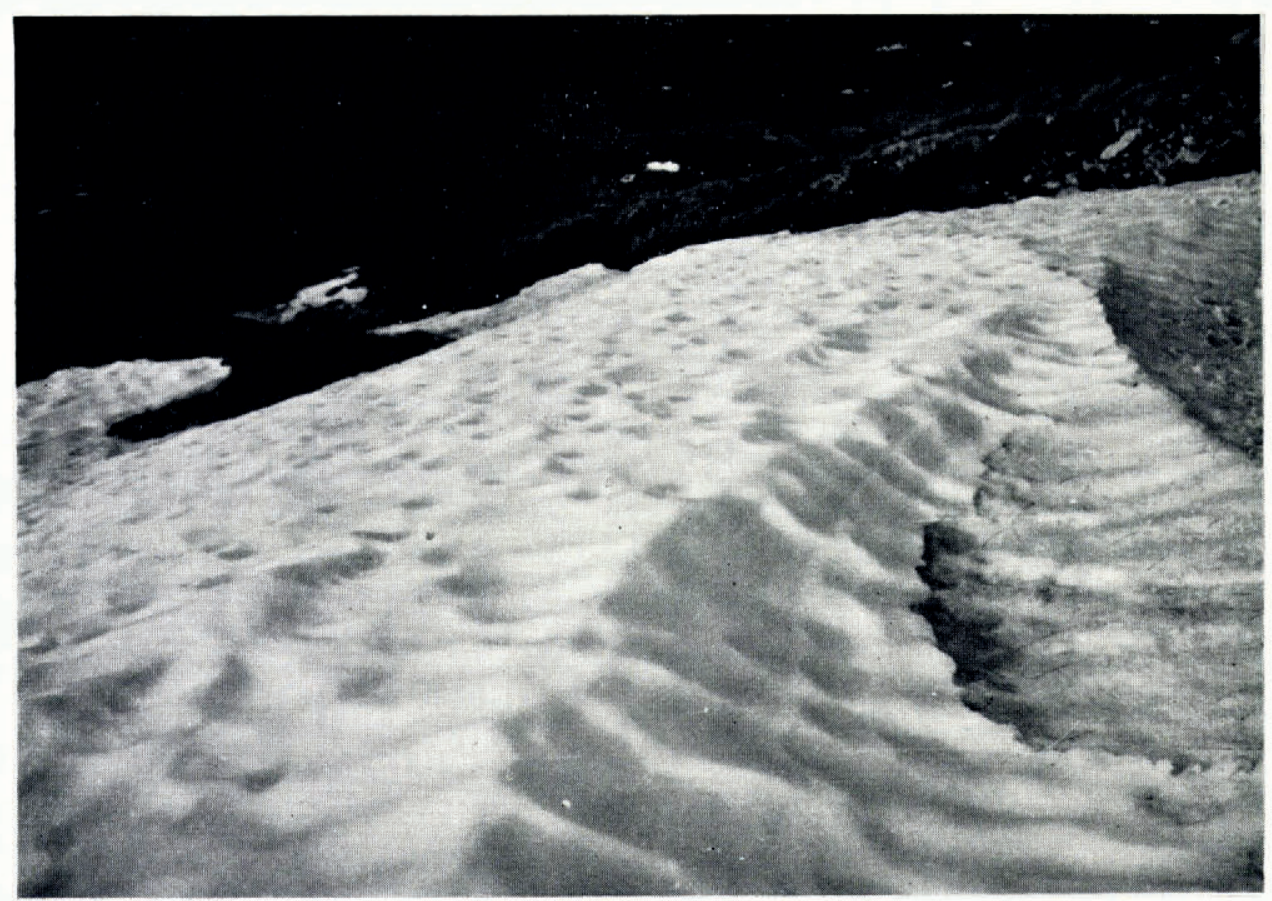

Fig. 4. Ablation polvgons on clean dirt-free snow. (Hala Gąsienicowa, Tatra Mountains, altitude I $520 \mathrm{~m}$ )

convincingly by Ball (I954) - are basically independent of each other. It is not difficult to find outstanding examples of typical ablation hollows on ideally clean (dirt-free) snow (Fig. 4). It must, however, be added that an admixture of foreign material, especially organic, facilitates the mechanism of formation of ablation hollows, makes them more prominent and also helps to preserve them. The significance of dirt in this problem calls for separate treatment.

\section{A Theory of Concentration of Dirt on Snow}

Mineral and organic admixtures deposited on the snow surface or in snow by water, wind, animals or man are subject to vertical and horizontal migration during the process of melting. They tend to be drawn together at certain points or lines (concentration) or they disperse in various directions ("deconcentration"). Both concentration, i.e. accumulation of dirt on the snow surface, and "deconcentration", i.e. dispersion of dirt, are due to the ablation process itself and may occur again and again in different phases of the same process.

The principles of concentration have been discussed by Ball (I954) in his theory of "normal trajectory". In the process of ablation, the particles of dirt on the snow are moved perpendicular to the retreating snow surface. However, Ball did not provide the explanation of the causes of this phenomenon. Let us, therefore, analyse the process more closely.

In ablation polygons on the snow surface, the concentration of dirt occurs on the ridges dividing the polygons. The process of removing dirt from the hollows will be referred to as "cleaning" the hollows. The more advanced is the process of ablation, i.e. the longer the snow surface is subjected to melting, the larger is the amount of material accumulated on the ridges between the hollows.

Our observations indicate that the process of "cleaning" the ablation hollows seems to be typical where dirt is of an organic origin. Out of six samples taken from very regular ablation 
polygons in the Tatra Mountains, as many as five contained over 30 per cent of organic material and one even more than 50 per cent. It consisted of grass stems and conifer needles, i.e. typical wind-borne material which is deposited on snow. In Vestspitsbergen, it was discovered that winter winds can deposit on the snow surface a layer of plant "chaff" which, in some places, may amount to more than $10 \mathrm{~cm}$ in thickness. Thus, the main characteristic of the dirt which is subject to concentration by ablation is that it is light. Moreover, this dirt is highly adhesive towards snow - it sticks to a wet snow surface as if it were glued and that is why the dirt assumes a position perpendicular to the slope of the snow surface during the ablation process. Firnified snow is also characterized by its adhesiveness. Spherical snow particles are surrounded by adhesive water which binds light material, especially organic, to the snow mass. Coarser mineral dirt such as sand or gravel is less adhesive and it slides down steep snow surfaces; thus gravitation prevents mineral dirt from following the principle of the "normal trajectory". Therefore, the coarser non-adhesive material does not fulfil the necessary conditions for the linear concentration of dirt which is typical of ablation polygons. This material usually slides down the sides and collects at the bottom of the hollows. When the amount of dirt becomes sufficient to protect the snow surface from ablation, dirt cones are developed instead of ablation polygons.

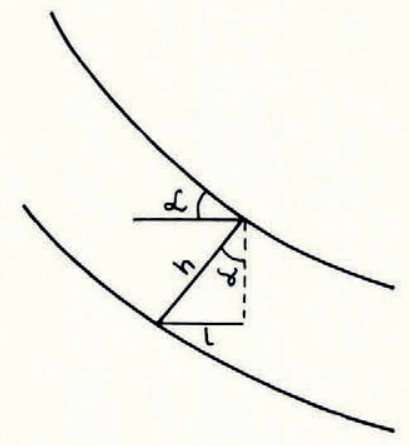

Fig. 5. Lateral migration (shifting) of material $(l)$, the thickness of the snow horizon is $h$ and the slope of the snow surface is a

Thus, in the course of ablation the adhesive material migrates downwards (the whole snow surface being lowered) and sidewards, depending on the slope of the surface of a relief microelement. If the micro-element happens to be an ablation hollow, lateral migration of material will depend on the surface slope of the hollow. It is not difficult to compute the value of this lateral daily "leap" $(l)$, since it is determined by the thickness of the snow layer melted during the day $(h)$ and by the local slope of the snow surface $(\alpha)$ as shown in Figure 5 :

$$
l=h \sin \alpha .
$$

It is evident from this formula that the linear concentration of material due to ablation depends on the slope of the micro-elements of the snow surface and not on the general slope of the whole snow patch, i.e. the slope angle (Fig. 6). In the case of ablation hollows the slope of the surface of a micro-element might be opposite in direction to the general slope angle. This is the explanation of such a frequently observed feature which appears to be characteristic of polygonal patterns on snow, i.e. that the pattern is unrelated to the general slope of a snow patch. 


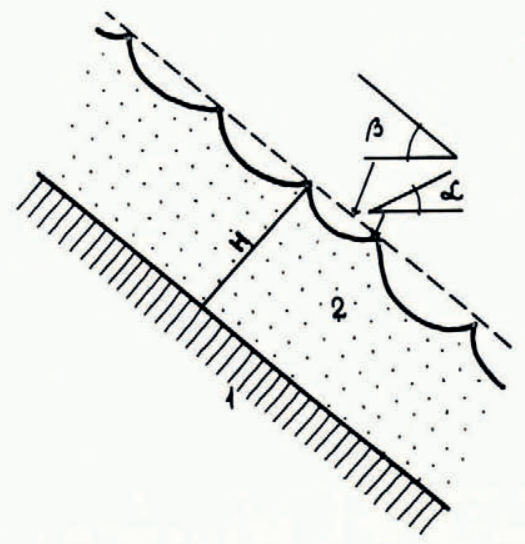

Fig. 6. The ratio of the slope of the micro-element surface $(\alpha)$ to the general angle of the slope $(\beta) . I$ rock, 2 snow, $H$ thickness of the snow patch
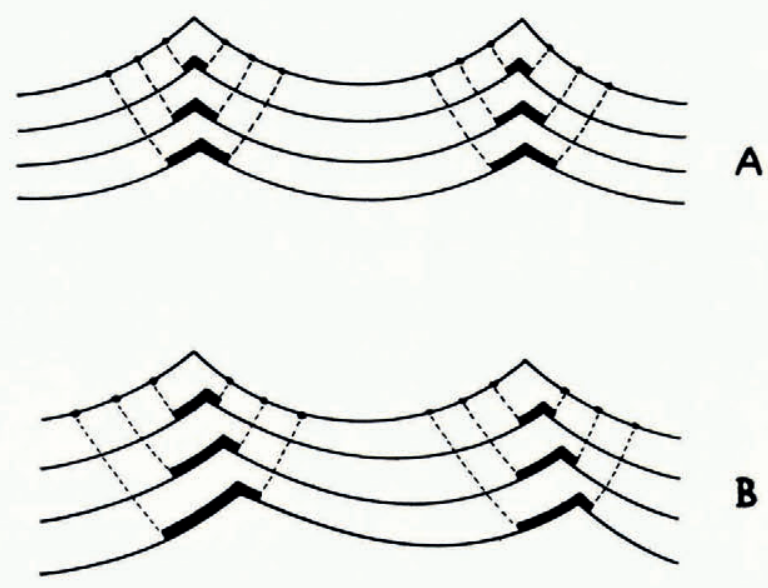

B

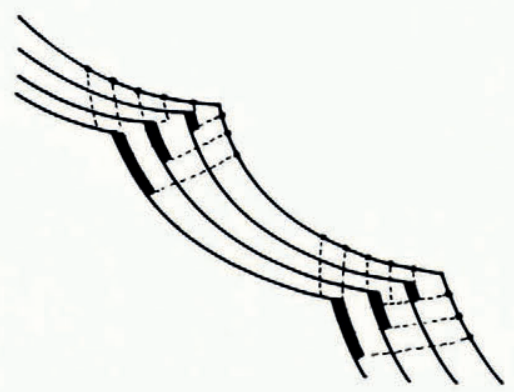

Fig. 7. Concentration of dirt in various patterns of ablation hollows; A symmetrical, $B$ asymmetrical, $C$ step-like 
Many daily periods of ablation $(h)$ occur during the wastage of a snow horizon $(H)$. From this it follows that the degree of concentration of material due to ablation is higher with a thicker snow cover. Hence the thickness of the snow horizon together with the micro-relief of its surface and the amount of foreign material on the snow surface determine the degree of concentration of dirt due to ablation.

The concentration of dirt occurs along the boundary between relief micro-elements whose surfaces are inclined in opposite directions, as described by Ball (Fig. $7 \mathrm{~A})$. The concentration is symmetrical if the rate of ablation is the same for two adjacent micro-elements; the dirt accumulates on both sides of the ridge (see Fig. I). When the rate of ablation varies because of an orientated, i.e. one-sided, exposure of the surface of micro-elements the result is an asymmetric concentration along the ridges (Fig. $7 \mathrm{~B}$ ). In step-like patterns of micro-elements on the snow surface (Fig. $7 \mathrm{C}$ ), as mentioned above, concentration proceeds mainly through shifting of the steps (see Fig. 3). In each of these cases it is exposure to the factor responsible for melting of the snow surface that determines the asymmetric development of dirt concentration. This factor need not always be solar radiation; asymmetric concentration of dirt may sometimes be caused by warm air currents which are at variance with exposure to solar radiation.

These theoretical schemes are based on actual instances of concentration forms due to ablation on snow patches in the Tatra Mountains.

It is worth noting that in the course of dirt concentration due to ablation elongated dirt particles, e.g. grass blades or conifer needles, are arranged in such a way that their long axes follow the ridge line (Fig. 8). The orientation of such dirt particles also appears to have resulted from the same ablation process that leads to the formation of hollows on the snow

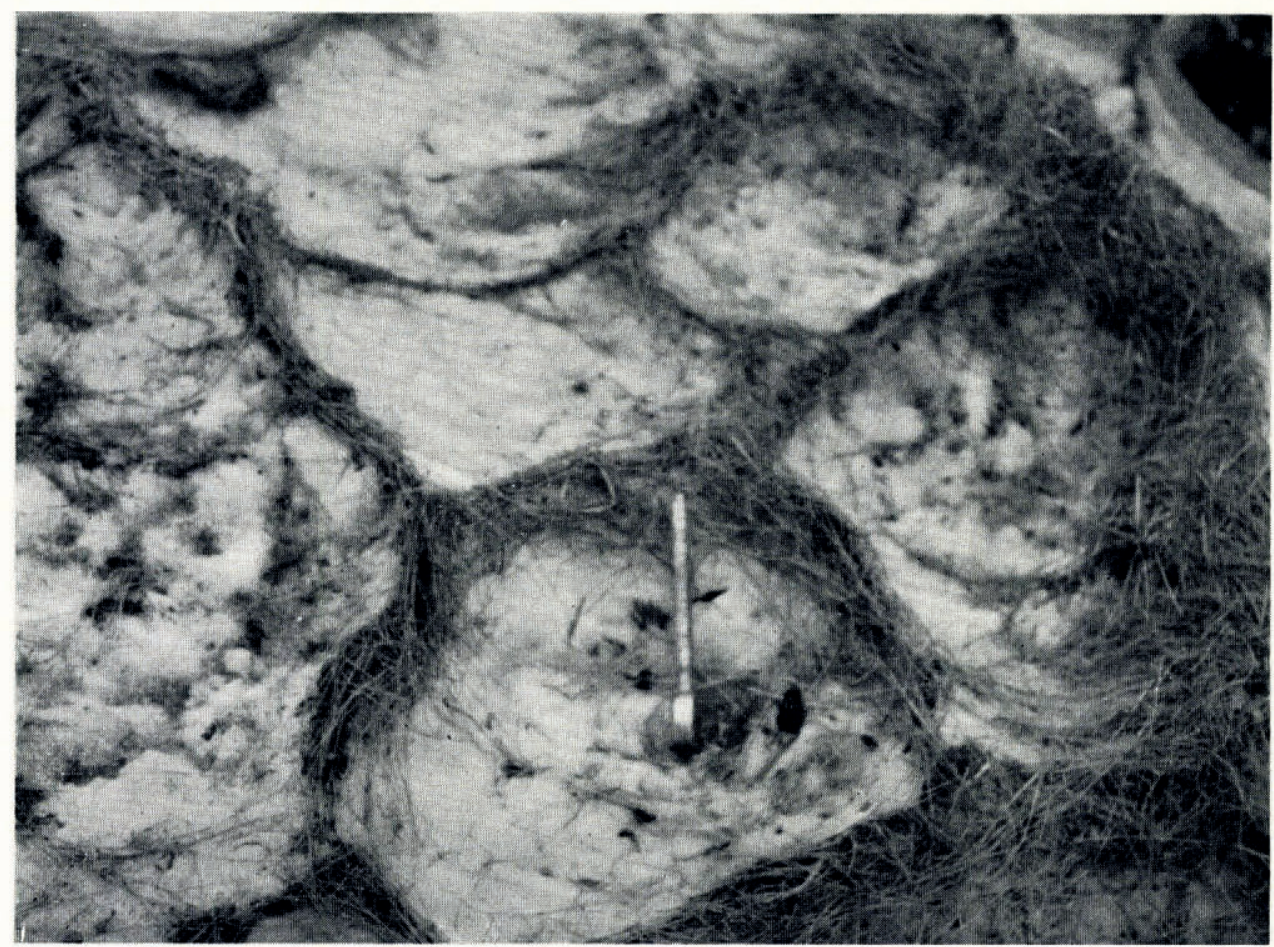

Fig. 8. Characteristic arrangement of blades of grass in ablation polygons; the arrangement is parallel to the orientation of the ridges 
surface. The increase in size of these forms from small to larger ones expands ablation surfaces in a pattern of concentric lines. Dirt particles are accordingly arranged along these lines to form a system of concentric rings. Our experiments have confirmed this explanation. Match sticks and conifer needles were scattered in different directions on the snow surface. After 2 days of melting and hollow formation the scattered material assumed a concentric arrangement. Also, the adhesiveness of dirt particles was of crucial importance since they followed closely changes in the snow surface.

The problems of ablation and its resulting forms led us to another series of experiments which were undertaken in 1966 and 1967 at the research station of the Polish Academy of Sciences which is located in a broad valley. A snow-field adjacent to the station was the object of our observations. The snow surface was covered with a mixture of mineral and organic material - coal dust, conifer needles, grass and mineral particles of soil - and the surface of the melting snow was observed throughout April, May and June. In these experiments the method recently applied by Ashwell and Hannell (r966) was largely followed. Squares of the mixture, varying in thickness from $\mathrm{I}$ to $20 \mathrm{~mm}$, were set out on the snow surface. In snow-fields covered with squares thicker than $10 \mathrm{~mm}$ ablation gave rise to convex forms but in those with less than Io mm concave forms appeared, i.e. ablation hollows (Fig. 9).

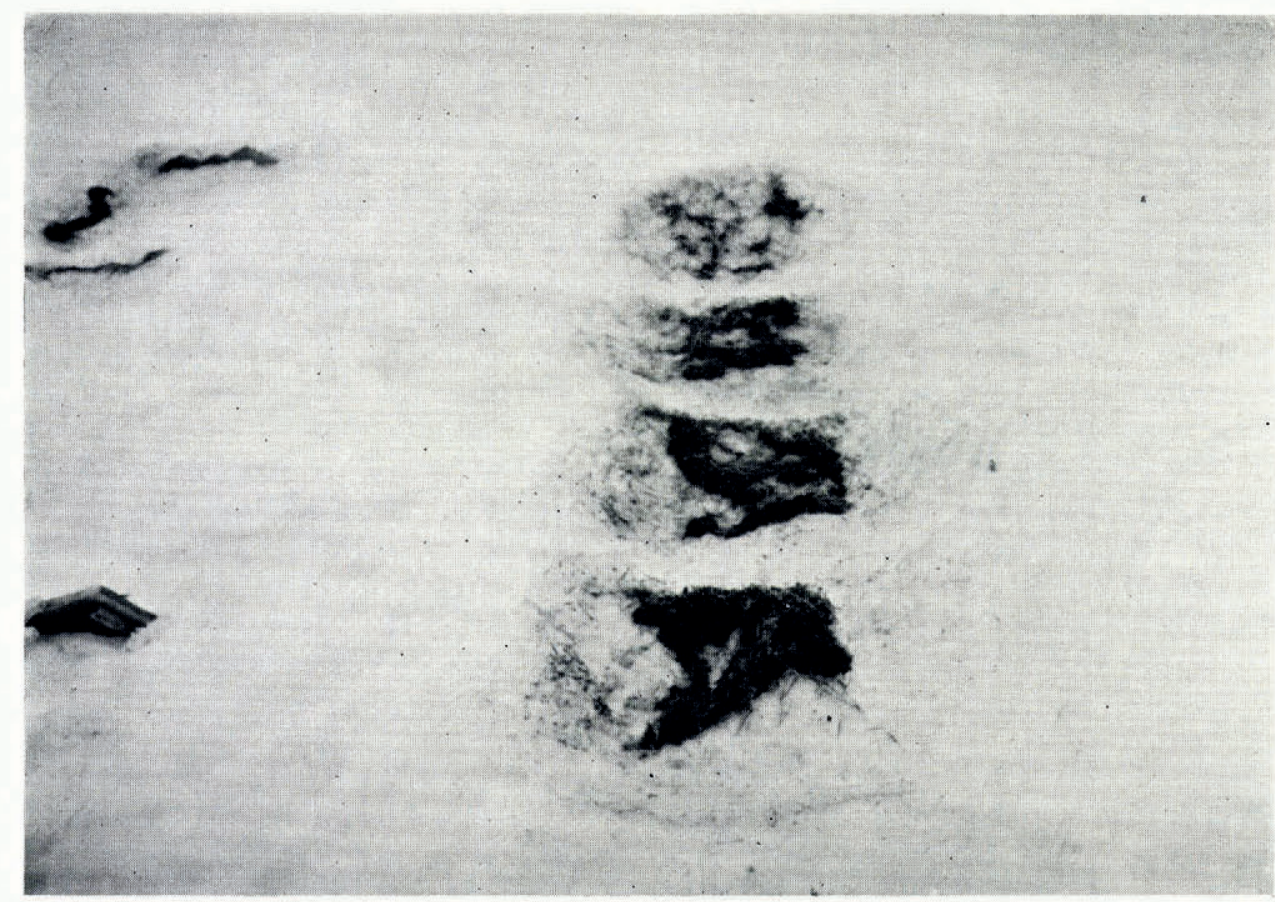

Fig. 9. Experimental research at the station Hala Gąienicowa, Tatra Mountains. Ablation forms corresponding to varying thicknesses of the covering material. Formation of polygonal elements in the experimental plot (top) where the covering material is thinnest (1 mm). May 1966

In the latter the processes of concentration and "deconcentration" of materials could easily be seen. The first stage of ablation is usually characterized by dispersion of the material on the snow surface, i.e. "deconcentration". This phenomenon is easily understood, since at this stage the melting results in a large asymmetric depression which is considerably larger than the square itself and within it smaller hollows are formed. The transition from the initial 
flat square to the hollow forms is accompanied by a marked enlargement of the surface covered with foreign material, i.e. its dispersion (Fig. 9). This process is most clearly seen when ablation of the snow surface is intense. Thus, for example, beginning with 6 May when sunny weather alternated with rain and the average air temperature was $10^{\circ} \mathrm{C}$ the surface was lowered by $18 \mathrm{~cm}$ during the first day. The depressions subsequently broadened and deepened. In the second day their widths were about $50 \mathrm{~cm}$ and their depths increased by I I cm (Fig. 9). Clearly, this stage was distinguished by "deconcentration" of the materials due to ablation. Apart from the ablation process, the wind was also responsible for some dispersion of the lighter particles covering the snow surface.

As the melting of the snow surface progressed we observed a regular concentration of material, by way of lateral migration (shifting) towards the ridges between the hollows (Fig. 9). In these experiments the degree of regularity was far below that occurring in natural conditions. There is nothing unusual in this, considering the limited scope of the experiment; it lasted only 5 days and involved a snow horizon only $32 \mathrm{~cm}$ thick, whilst in the natural process both the duration and the extent of selective concentration are considerably greater. In addition, the area around the station, i.e. an unsheltered plot exposed to solar ablation, does not provide optimal conditions for the development of ablation hollows. We could not fully account for the fact that cluster-like concentrations of materials appeared in the initial stage of ablation.

While examining the process of dirt concentration due to ablation our attention was directed to the question of the relation between concentration and the hollow-like relief of ablation polygons. This is by far the most satisfactory example of linear concentration. The major effects of the concentration appear on the ridges between three or four contiguous polygons. The intersections of the ridges form cones composed of the overlying material, and it may be so thick that it functions as a protective layer. Therefore, there is a relation between the two fundamental forms of ablation of the snow surface - polygonal hollows and dirt cones.

Other instances of linear concentration of dirt can be found in places where the ablating snow surface meets the surface of old frozen snow. A straight streak of dirt can be distinctly seen against the background of clean snow. Such a linear concentration can be explained as follows. Ablation depressions and the hollows which "clean" the snow are developed laterally. Their development is retarded in places where a hard margin of old snow is exposed on the surface and these become places for the accumulation of dirt expelled from the snow.

To conclude this analysis, it seems well worth stressing again that it is valid only in relation to the problem of the concentration of foreign material by ablation (Jahn, I96I). Concentration resulting from the action of water and wind may also lead to linear effects. During the ablation process, streaks and dust deposited by wind remain on the snow surface for a long time (Fig. IO).

\section{Some Fagtors Controlling the Development of Polygonal Hollows on Snow}

The process of melting of the snow surface is responsible for the formation of certain microrelief features on the surface. The striking regularity of this micro-relief, frequently assuming a pattern of polygonal hollows, has not however been fully explained. The basic question is whether the origin of these forms is to be attributed to the snow structure or to specific meteorological conditions.

Ablation polygons occur only on crystallized spring snow; they are never found on new snow and are therefore partly dependent on a certain snow structure. On the other hand, no connection can be claimed to exist between the hollows and the stratification of the snow. On the contrary, the surface of the hollows often cuts the snow stratification (Fig. I I). This conclusion has been confirmed by measurements of snow density. The snow forming the ridges does not differ in density from that inside the hollows and, if there is any difference at all, it results from the differences in density of individual horizons. Melt water penetrating into the 


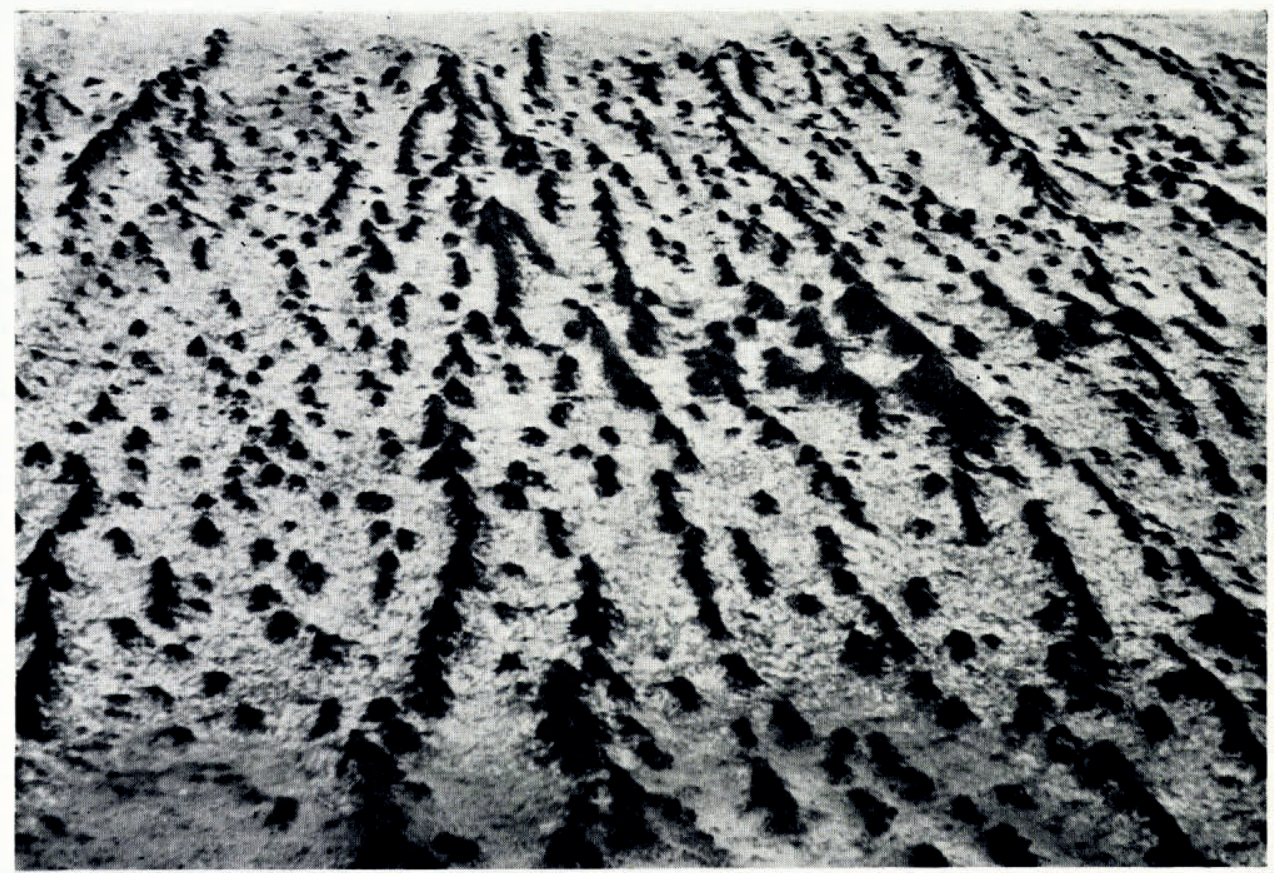

Fig. 10. Linear concentration of material due to orientated action of the accumulation factor. (Hornsundfjord, Vestspitsbergen)

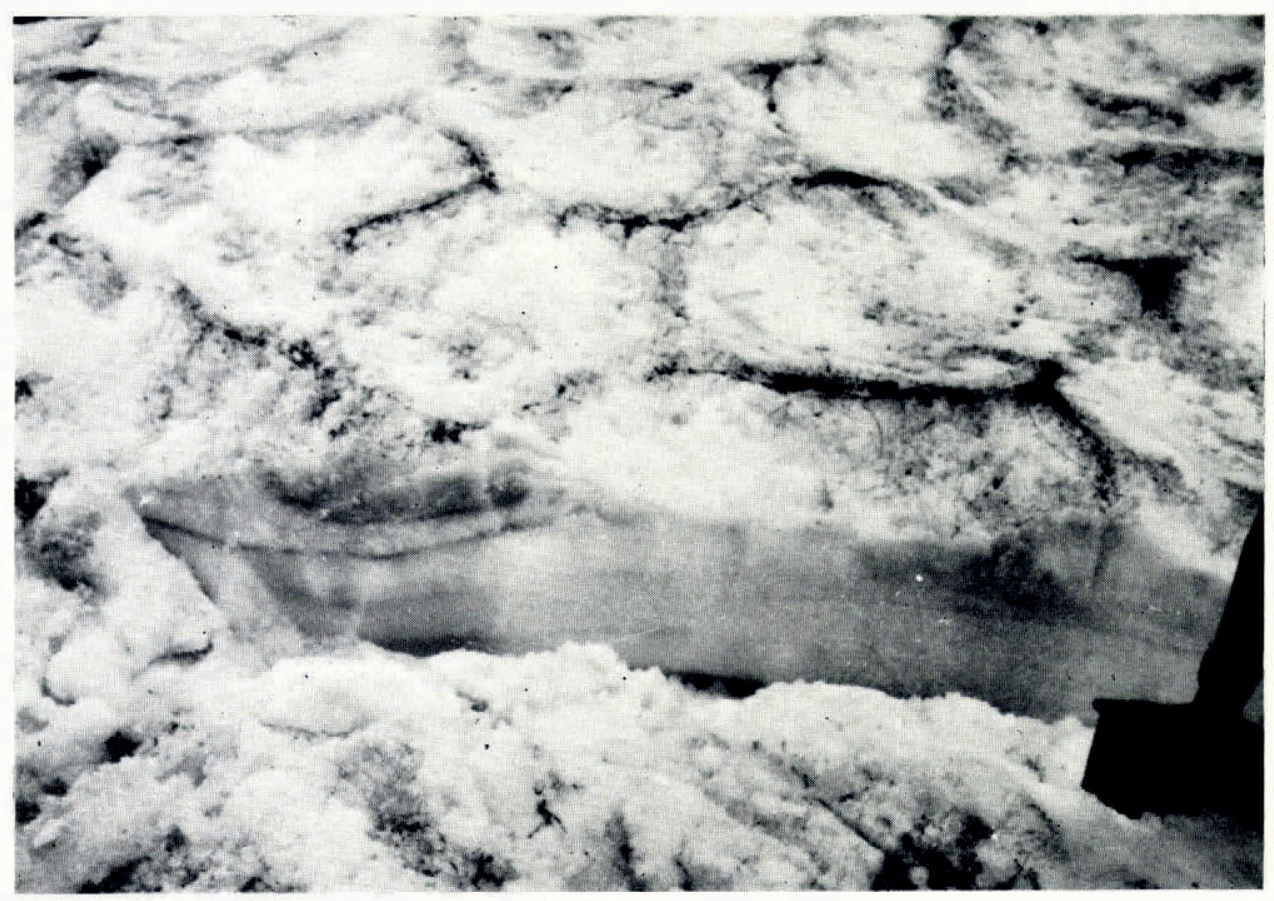

Fig. 11. Ablation polygons near Czarny Staw Gąsienicowy in the Tatra Mountains, July 1965. The surface of the polygons is not consistent with the stratification of the snow 
snow may be responsible for the formation of vertical pillars, as suggested by Lliboutry (1964-65), but the related forms on the ablation surface would then appear as protuberances instead of patterns of polygonal ridges.

The initial stage of the formation of polygonal hollows due to ablation can be referred to the action of meteorological factors, especially to turbulence currents of warm air, as demonstrated by Leighly (1948) and Richardson (1954). Ashwell and Hannell (I966) noticed the connection between polygons and winds but, since they regarded the dispersion of dirt as the cause instead of an effect of the development of the hollows, they were thus prevented from properly accounting for the origin of these forms. * The turbulence theory seems to be closest to the truth though we are not quite familiar with the details. The following evidence may be adduced to support this theory.

Polygonal ablation hollows appear in their most definite form in sheltered depressions and concavities; and the nearer they are to the rocky surface of the slope the better developed they become. We have positive evidence that distinctive deep hollows were formed in an area adjacent to a rock wall which was sending forth heated air over the snow-field, while in the part which had no direct contact with the rocky surface the hollows were hardly visible. Where the ablation hollows are more readily formed, there is a greater thermal gradient between the surface of a snow patch and the air current which descends gently from the rocky slopes. That is why the hollows can develop only after a large part of the rocky surface has been rendered snow-free, thus acting as a source of thermal turbulence. We believe that air currents of this type provide the ideal conditions for the formation of ablation micro-elements, i.e. small concave forms which make the nuclei of the hollows. Air turbulence does not cause the polygonal pattern of the ridges; this regular pattern develops from the growth and mutual interference of irregular basin-like and circular hollows which develop laterally until they overlap, forming patterns of polygonal ridges. In this they are analogous to patterned ground which starts from sorted circles and develops laterally into polygonal (pentagonal and hexagonal) systems.

There is another point well worth emphasizing, i.e. the one indicating the existence of horizontal movement of the snow mass during ablation. Wilson (1953) referred to "the shrinkage of the snow surface associated with ablation", which he had ascertained experimentally by arranging a row of stones on the snow. In the present experiments the ablation micromovements of the snow surface were observed in the following way. We placed strips of mineral and organic material on the snow surface. In the following 5 days the process of melting and lowering of the snow surface resulted in the formation of depressions and consequently the strips were deformed-they were twisted, contracted and expanded, the contortions amounting to as much as $90^{\circ}$ (Fig. I2). These micro-movements took the form of sliding of the superficial snow mass (the process is analogous to micro-solifluction on the surface of soil) and they were quite independent of the processes of dispersion and concentration of dirt on snow. The movement was probably caused by the varying degrees of compaction of the snow mass which had been saturated with water. The horizon of snow immediately exposed to ablation was more rapidly transformed to firn than that part of the snow surface which was covered by the strips of dirt. Because of the downward water drainage, a spongy mass formed on the dirt-free surface while the snow protected by dirt slid towards areas of reduced density. It was characteristic that this snow continued to retain its identity. When the strips became twisted their lengths (as measured by the distance between the extreme points) diminished and the spaces between them increased (Fig. 12). The experiment therefore provides the evidence for the presence during ablation of horizontal movement in the superficial snow horizons. It is also indicative of a high degree of cohesion of the snow mass, since the movement is accompanied by plastic deformation and not disruption of micro-elements.

* In figure $\mathrm{I} I$ in the paper by Ashwell and Hannell (1966) one can see ablation polygons with dirt, and in addition to these there are similar forms without dirt. 


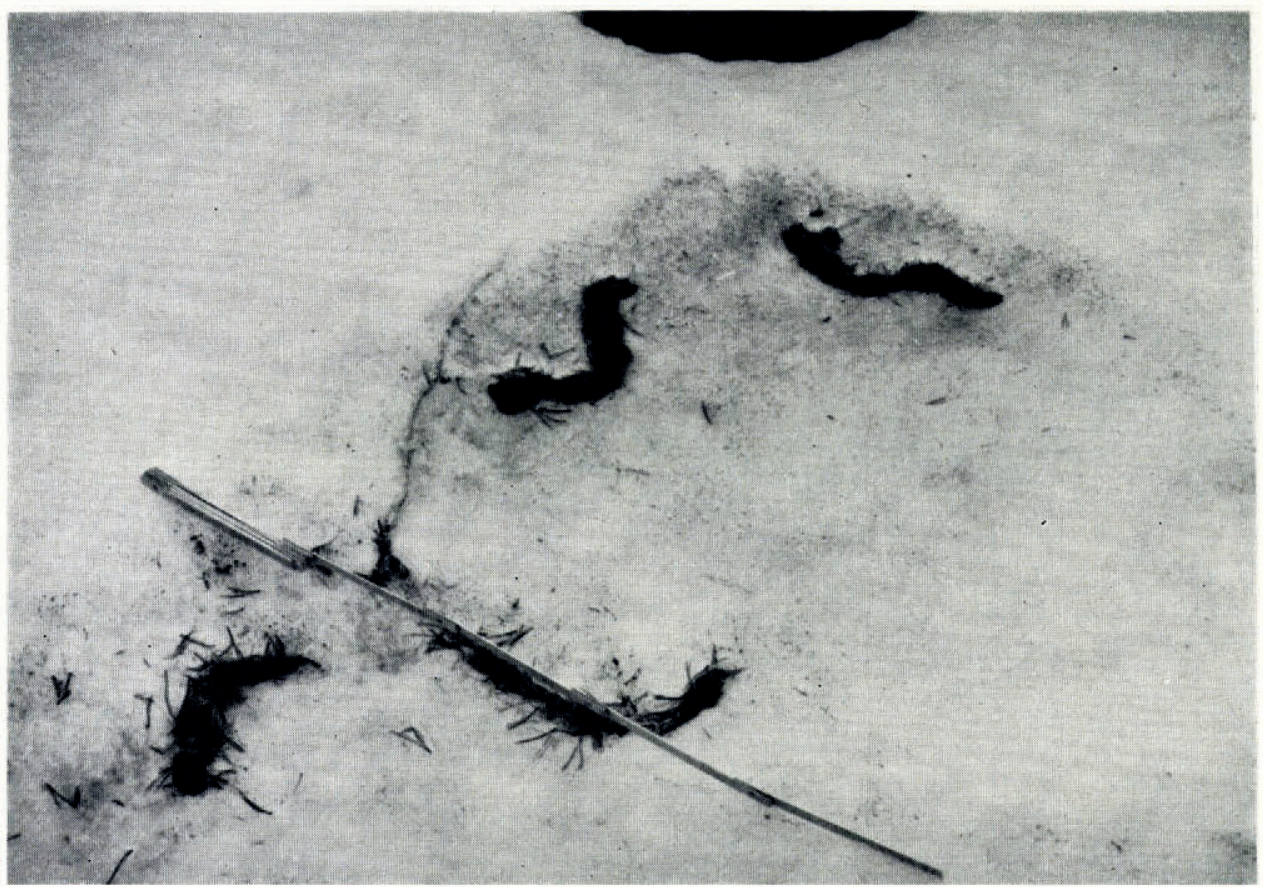

Fig. 12. Deformed strips provide experimental evidence for horizontal movement of the ablation surface of snow. (Hala Gąsienicowa, Tatra Mountains, May Ig66)

\section{Final Remarks on the Origin of Ablation Hollows}

Polygonal forms on snow are due to the action of an external factor, i.e. ablation, chiefly by air masses. There is a genetic relation between the external and internal forms of snow patches, and their vertical walls appear to be one of the connecting elements. It is not only the polygons but also the ablation steps on the snow that belong to this type of phenomenon. All of these constitute the ablation micro-relief of the snow surface. The actual shape of the micro-elements is less dependent on the slope of the snow surface than the orientation of the factor that is responsible for the melting of snow, e.g. the orientation of winds.

The presence of dirt on snow does not by itself initiate the formation of a micro-relief on the snow surface. In the course of the ablation process, dirt is subject to concentration or "deconcentration", depending on the degree of adhesion between snow and dirt and on the character of the micro-relief forms.

The geometrical relief of the snow surface is probably caused by the unequal distribution of ablation hollows, due to turbulence in air masses. The final regular form of the hollows is a reflection of their interference as they grow and develop and not of their initial distribution which may be random. This development is simultaneous with the changes in the physical properties of the snow and its structure (the increase in snow density, recrystallization due to regelation, the expansion of crystals, the firn balls, the action of adhesive water, etc.). It is only at this stage that a thorough sorting out of dirt is begun, e.g. the concentric arrangement of blades of grass; this tendency to geometric forms results in an amazing polygonal pattern. In this way the shapes of snow and ice particles are changed, their mutual arrangement is modified and even the existence of mass micro-movements in the superficial snow horizon is revealed. Although the details of this process have not as yet been fully studied, the present 
state of knowledge seems to indicate that consistency and regularity of ablation forms correspond to regularity of structural changes and consequently to regularity in the snow metamorphism.

MS. received 25 April 1967

\section{REFERENCES}

Ashwell, I. Y., and Hannell, F. G. 1966. Experiments on a snow-patch in the mountains of Sweden. Fournal of Glaciology, Vol. 6, No. 43, p. 135-44.

Ball, F. K. 1954. Dirt polygons on snow. Weather, Vol. 9, No. 10, p. 322-23.

Dobrowolski, A. B. 1923. Historja naturalna lodu. Warszawa, Palac Staszica.

Hamberg, A. 1907. Die Eigenschaften der Schneedecke in den lappländischen Gebirgen. Naturwissenschaftliche Untersuchungen des Sarekgebirges in Schwedisch-Lappland, Abt. 3 (1).

Heim, A. 1885. Handbuch der Gletscherkunde. Stuttgart, J. Engelhorn.

Jahn, A. 196r. Quantitative analysis of some periglacial processes in Spitsbergen. Nauka o Ziemi II, Uniwersytet Wroclawski im. Bolestawa Bieruta, Zeszyty Naukowe, Nauki Przyrodnicze, Ser. B, Nr. 5, p. 3-54.

Klapa, M. 1963. Report on research work carried out at the Scientific Station of the Institute of Geography of the Polish Academy of Sciences in the Tatra Mts. (Hala Gąsienicowa) in 1960-1961. Przegląd Geograficzny, Tom 35, Zeszyt 2, p. $22 \mathrm{I}-37$.

Leighly, J. 1948. Cuspate surfaces of melting ice and firn. Geographical Review, Vol. 38, No. 2, p. $301-06$.

Lliboutry, L. 1964-65. Traité de glaciologie. Paris, Masson et Cie. 2 vols.

Richardson, W. E. 1954. Dirt polygons. Weather, Vol. 9, No. 4, p. 1 i 7-2 1 .

Richardson, W. E., and Harper, R. D. M. 1957. Ablation polygons on snow-further observations and theories. Journal of Glaciology, Vol. 3, No. 21, p. 25-27.

Sekyra, J. 1964. Cryogeological phenomena in the north Pamir (central Trans-Alai). Biuletyn Peryglacjalny (Łódź), Nr. 14, p. 31 I-I9.

Westman, J. 1913. Beobachtungen über den Wasseraustausch zwischen der Schneedecke und der Luft im Mittelschwedischen Tieflande. Meddelanden från Hydrofiska Byrån (Stockholm), No. 5 .

Wilson, J. W. 1953. The initiation of dirt cones on snow. Fournal of Glaciology, Vol. 2, No. 14, p. $281-87$. 